\title{
SaaS ERP Adoption Intent: Explaining the South African SME Perspective
}

\author{
Julian Faasen $^{1}$, Lisa F. Seymour ${ }^{1}$, and Joachim Schuler ${ }^{2}$ \\ ${ }^{1}$ Information Systems Department, University of Cape Town, Private Bag, \\ Rondebosch 7700, South Africa \\ Lisa. Seymour@uct.ac.za \\ ${ }^{2}$ Pforzheim University, Tiefenbronnerstrasse 65, \\ 75175 Pforzheim, Germany \\ Joachim.Schuler@hs-pforzheim.de
}

\begin{abstract}
This interpretive research study explores intention to adopt SaaS ERP software within South African SMEs. Semi-structured interviews with participants from different industry sectors were performed and seven multidimensional factors emerged explaining the current reluctance to adoption. While, improved IT reliability and perceived cost reduction were seem as benefits they were dominated by other reasons. Reluctance to adopt was attributed to systems performance and availability risk; sunk cost and satisfaction with existing systems; data security risk; loss of control and lack of vendor trust; and finally functionality fit and customization limitations. The findings provide new insights into the slow SaaS ERP adoption in South Africa and provide empirically supported data to guide future research efforts. Findings can be used by SaaS vendors to address perceived shortcomings of SaaS ERP software.
\end{abstract}

Keywords: Software as a Service, Cloud computing, Enterprise Resource Planning, SaaS ERP, South African SME, Information Systems adoption.

\section{Introduction}

Small and medium enterprises (SMEs) are major players in every economy and make a significant contribution to employment and Gross Domestic Product (GDP) [1]. In the past, many organizations were focused on local markets, but have been forced to respond to competition on a global level as well [2]. The role of the SME in developing countries such as South Africa is considered critical in terms of poverty alleviation, employment creation and international competitiveness [3]. However, resource limitations have made it difficult for many smaller organizations to enter new markets and compete against their larger counterparts. Thus SMEs in all countries are forced to seek innovative ways to become more efficient and competitive within a marketplace rife with uncertainty. Adoption of Information Systems (IS) is viewed as a way for SMEs to become more competitive and to drive business benefits such as cost reduction, improved profitability, enhanced customer service, new market growth opportunities and more efficient operating relationships 
with trading partners [4]. Many organizations have adopted Enterprise Resource Planning (ERP) software in an attempt to achieve such benefits.

ERP software facilitates the integration of cross-functional business processes in order to improve operational efficiencies and business performance. If used correctly, ERP software can drive bottom-line results and enhance competitive advantage. Whilst most large organizations world-wide have managed to acquire ERP software [5], it has been reported that many SMEs have been unwilling to adopt ERP software due to the high cost and risk involved [6]. However, an alternative to on-premise enterprise software has been made possible with the advent of the Software as a Service (SaaS) model.

SaaS as a subset of cloud computing involves the delivery of web-based software applications via the internet. SaaS is essentially an outsourcing arrangement, where enterprise software is hosted on a SaaS vendor's infrastructure and rented by customers at a fraction of the cost compared with traditional on-premise solutions. Customers access the software using an internet browser and benefit through lower upfront capital requirements [7], faster deployment time [8]; [9], improved elasticity [10], flexible monthly installments [11] and more predictable IT budgeting [8]; [12]. Countering these benefits are concerns around software reliability, data security [12]; [13]; [14] and long-term cost savings [15]. Customization limitations [16] and integration challenges [10] are considered major concerns relating to SaaS offerings. Furthermore, concerns relating to data security and systems availability have raised questions as to the feasibility of SaaS for hosting mission-critical software.

Despite the perceived drawbacks of SaaS, Gartner suggests that SaaS ERP solutions are attracting growing interest in the marketplace [17]. Traditional ERP vendors such as SAP have begun expanding their product ranges to include SaaSbased offerings. The success of Salesforce's SaaS CRM solution provides further evidence that the SaaS model is capable of delivering key business functionality. However, the adoption of SaaS ERP software has been reported as slow [17] and appears to be confined to developed countries. Despite the plethora of online content promoting the benefits of SaaS ERP software, there is a lack of empirical research available that explains the slow rate of adoption. Thus, the purpose of this study is to gain an understanding of the reluctance to adopt SaaS ERP software within South African SMEs. This research is considered important as SaaS is a rapidly growing phenomenon with widespread interest in the marketplace. Furthermore, this study aims to narrow the research gap by contributing towards much-needed empirical research into SaaS ERP adoption.

\section{$2 \quad$ Literature Review}

A number of pure-play SaaS vendors as well as traditional ERP providers are offering ERP software via the SaaS model. Krigsman [18] summarized the major SaaS ERP vendors and offerings and found that many are offering the major six core modules: Financial Management, Human Resources Management, Project Management, Manufacturing, Service Operations Management and Supply Chain Management. 
However, according to Aberdeen Group, only nine SaaS vendors actually offered pure SaaS ERP software and services [19]. A Forrsights survey found that $15 \%$ of survey participants were planning adoption of SaaS ERP by 2013 [20]. However, two-thirds of those firms were planning to complement their existing on-premise ERP software with a SaaS offering. Only $5 \%$ of survey participants planned to replace most/all of their on-premise ERP systems within 2 years (from the time of their survey). These findings provide evidence of the slow rate of SaaS ERP adoption. It should also be noted that popular SaaS ERP vendors such as Netsuite and Epicor were not yet providing SaaS ERP products in South Africa during the time of this study in 2011.

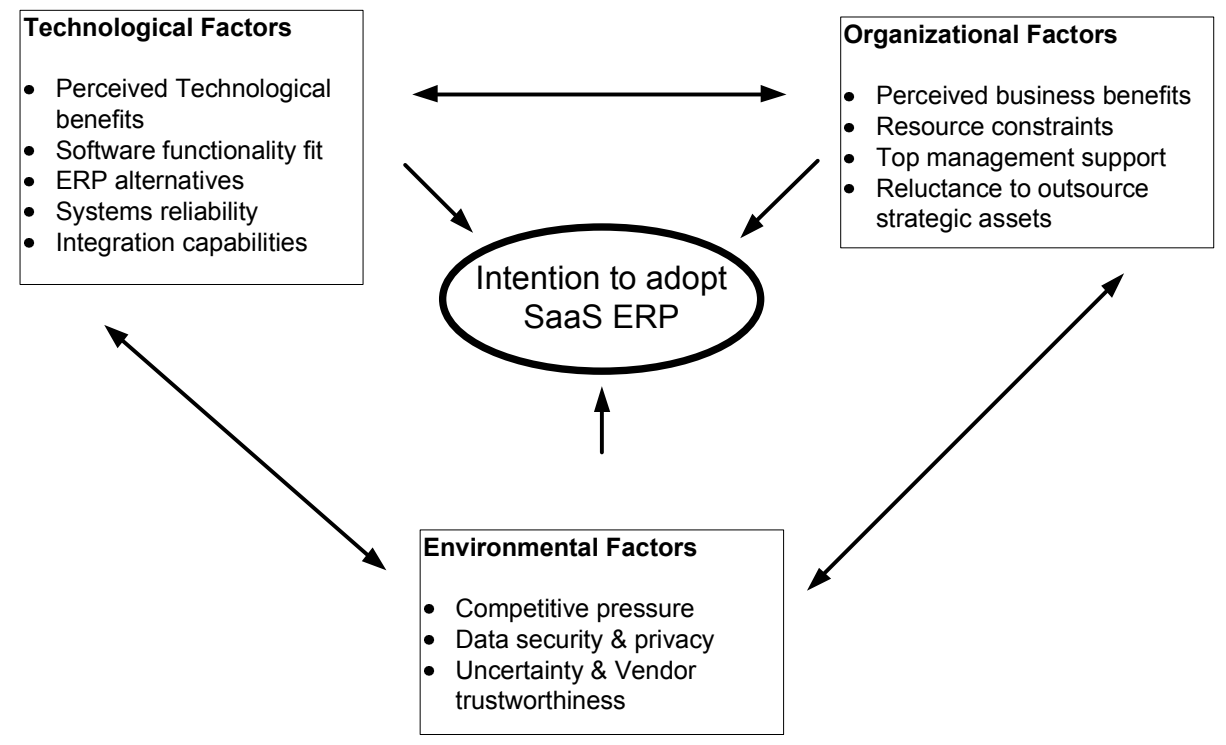

Fig. 1. Model derived from the broad literature

Given the scarcity of SaaS ERP literature, a literature review of the factors potentially influencing this slow adoption was performed based on prior studies relating to on-premise ERP adoption, IS adoption, SaaS, ASP and IS outsourcing (Figure 1). The major factors identified are structured according to the Technology-Organization Environment (TOE) framework [21]. For parsimonious reasons only these factors that were confirmed from our results are discussed in the results section of this paper.

\section{$3 \quad$ Research Method}

The primary research question was to identify why South African SMEs are reluctant to consider the adoption of SaaS ERP. Given the lack of research available an inductive interpretive and exploratory approach was deemed appropriate. The study also contained deductive elements as past research was used to generate an initial model. Walsham [22] posits that past theory in interpretive research is useful as a 
means of creating a sensible theoretical basis for informing the initial empirical work. To reduce the risk of relying too heavily on theory, a significant degree of openness to the research data was maintained through continual reassessment of initial assumptions [22].

Non-probability purposive sampling [23] was used to identify suitable organizations to interview and ethics approval from the University was obtained prior to commencing data collection. The sample frame consisted of South African SMEs with between 50 and 200 employees [24]. One participating organization contained 250 employees and was included due to difficulties finding appropriate interview candidates. SMEs in different industry segments were targeted to increase representation. Furthermore, SMEs that operated within traditional ERP-focussed industries (e.g. manufacturing, logistics, distribution, warehousing and financial services, etc.) were considered to improve the relevance of research findings. The majority of participants interviewed were key decision makers within their respective organizations to accurately reflect the intention to adopt SaaS ERP software within their respective organizations. Table 1 provides a summary of company and participant demographics.

Table 1. Company and Participant Demographics

\begin{tabular}{|c|c|c|c|c|c|}
\hline $\begin{array}{l}\text { Company } \\
\text { code }\end{array}$ & $\begin{array}{l}\text { Participant } \\
\text { Code }\end{array}$ & Position & Experience & Industry & Employees \\
\hline $\mathrm{A}$ & A1 & $\begin{array}{l}\text { Digital } \\
\text { Director }\end{array}$ & 10 years + & $\begin{array}{l}\text { Book publishing } \\
\& \text { distribution }\end{array}$ & 250 \\
\hline A & A2 & $\begin{array}{l}\text { IT } \\
\text { Operations } \\
\text { Manager }\end{array}$ & 17 Years & $\begin{array}{l}\text { Book publishing } \\
\text { \& distribution }\end{array}$ & 250 \\
\hline B & B & Head of IT & 20 years + & Financial Services & 120 \\
\hline $\mathrm{C}$ & $\mathrm{C} 1$ & $\begin{array}{l}\text { Chief } \\
\text { Operating } \\
\text { Officer }\end{array}$ & 20 years + & $\begin{array}{l}\text { Specialized } \\
\text { Health Services }\end{array}$ & 50 \\
\hline $\mathrm{C}$ & $\mathrm{C} 2$ & $\begin{array}{l}\text { IT } \\
\text { Consultant }\end{array}$ & 7 years + & $\begin{array}{l}\text { Specialized } \\
\text { Health Services }\end{array}$ & 50 \\
\hline $\mathrm{D}$ & $\mathrm{D}$ & $\begin{array}{l}\text { Financial } \\
\text { Director }\end{array}$ & 20 years + & $\begin{array}{l}\text { Freight Logistics } \\
\text { Provider }\end{array}$ & 200 \\
\hline $\mathrm{E}$ & $\mathrm{E}$ & $\begin{array}{l}\text { Managing } \\
\text { Director }\end{array}$ & 20 years + & $\begin{array}{l}\text { Medical } \\
\text { Distribution }\end{array}$ & 137 \\
\hline
\end{tabular}

Data was collected using semi-structured interviews with questions which were initially guided by a priori themes extracted from the literature review. However, the researcher practised flexibility by showing a willingness to deviate from the initial research questions in order to explore new avenues [25].

Data analysis was conducted using the general inductive approach, where research findings emerged from the significant themes in the raw research data [26]. To enhance the quality of analysis member checking, thick descriptions, code-recode and audit trail strategies [27] were employed. 


\section{$4 \quad$ Data Analysis and Discussion}

During interviews, it was apparent that the term "ERP" was sometimes used to represent functionality provided by a number of disparate systems. Thus the term ERP was used in terms of how the participant's companies used their business software collectively to fulfil the role of ERP software. Table 2 below provides an overview of the software landscape for each of the companies interviewed. Companies used a combination of off-the-shelf, bespoke, vertical ERP or modular ERP applications.

In this study, intention to adopt SaaS ERP software is defined as the degree to which the organization (SME) considers replacing all or most of their on-premise enterprise software with SaaS ERP software. SaaS ERP was defined as web-based ERP software that is hosted by SaaS ERP vendors and delivered to customers via the internet. The initial engagement with participants focussed primarily on multi-tenant SaaS ERP offerings, implying that a single instance of the ERP software would be shared with other companies.

Table 2. Software landscape for companies interviewed

\begin{tabular}{llllll}
\hline Current Software Landscape & \multicolumn{2}{l}{ Company code } & & & \\
& A & B & C & D & E \\
Using industry-specific ERP software & Yes & No & No & No & No \\
Using component-based ERP software & No & No & Yes & Yes & Yes \\
Using off-the-shelf software & Yes & Yes & Yes & Yes & Yes \\
Using Bespoke (customized) software & Yes & Yes & Yes & Yes & No \\
Implementation of ERP software in progress & No & Yes & No & No & No \\
\hline
\end{tabular}

At the time of this study SaaS ERP was not easily available from vendors in South Africa. Irrespective of the availability, none of the companies interviewed had an intention of adopting SaaS ERP software in the future. However, one participant suggested a positive intention towards adoption of SaaS applications: "Microsoft CRM is available on the SaaS model...that's the way companies are going and we are seriously considering going that way" (Participant B). His company was in the process of planning a trial of SaaS CRM software. However, Participant B's organization was also in the process implementing on-premise ERP software. The findings are inconsistent with global Gartner and Forrsights surveys which reported a willingness and intention to adopt SaaS ERP software within small and mid-sized organizations [28]; [20].

The main objective of this research was to explore the factors that impacted the reluctance to consider SaaS ERP software adoption within South African SMEs. The following 7 themes emerged and are discussed in the following sections:

1. Perceived cost reduction (driver)

2. Sunk cost and Satisfaction with existing system (inhibitor)

3. Systems performance and availability risk (inhibitor) 
4. Improved IT reliability (driver)

5. Data security risk (inhibitor)

6. Loss of control and Vendor trust (inhibitor)

7. Functionality Fit and Customization Limitations (inhibitor)

\subsection{Perceived Cost Reduction}

In line with the literature cost reductions were envisaged in terms of initial hardware and infrastructure [30]; [31]; [10] and were perceived as having a positive effect on intention to adopt SaaS ERP. However, participants also referred to the high cost of maintaining their on-premise ERP applications and potential long term operational cost savings with SaaS ERP.

“..it's the ongoing running costs, support and maintenance, that makes a difference" (Participant B).

However, these high costs were often justified in terms of the value that their onpremise systems provided:

“...if it's considered important then cost is very much a side issue” (Participant D).

\subsection{Sunk Cost and Satisfaction with Existing Systems}

The intention to adopt SaaS ERP was negatively affected by sunk cost and satisfaction with their existing systems. This was the 2 nd most dominant theme. Sunk cost represents irrecoverable costs incurred during the acquisition and evolution of their existing IT systems.

“...if you're company that's got a sunk cost in ERP...the hardware and staff and training them up... what is the benefit of moving across to a SaaS model?” (A1).

"...if we were starting today with a clean slate, with not having a server room full of hardware, then definitely...SaaS would be a good idea" (D)

Satisfaction with existing systems relates to the perception of participants that their existing enterprise software was fit for purpose.

“...whenever you've got a system in place that ticks $90 \%$ of your boxes and it's reliable...why change, what are we going to gain, will the gain be worth the pain and effort and the cost of changing” (A1).

The effect of sunk costs towards SaaS ERP adoption intent could not be verified within academic literature but is consistent with the 2009 Aberdeen Group survey, where organizations showed reluctance towards adoption due to past investment in IT [28]. Both sub-themes were also related to a lack of perceived benefits towards changing to alternatives such as SaaS ERP.

“...you're constantly investing in the current system and you're depreciating those costs over three, five, years. So... if you've got those sunk costs...even if you could save $30 \%$ you'd have to weigh it up around the investment" (Al).

This is in agreement with research which states that organizations adopt technology innovations only if they consider the technology to be capable of addressing a perceived performance gap or to exploit a business opportunity [32]. 


\subsection{System Performance and Availability Risk}

Concerns over systems performance and availability risk were the dominant reasons for the reluctance to adopt SaaS ERP. This was commented on by all participants. Systems performance and availability risk concerns were primarily related to bandwidth concerns in South Africa. More specifically, bandwidth cost, internet latency limitations and bandwidth reliability (uptime) were considered factors which impacted the performance and availability of SaaS ERP solutions, thus impacting adoption intent. These findings are in line with literature which suggests that systems performance and availability concerns have a negative impact on ASP adoption [33] and SaaS adoption [34].

"The cheapest, I suppose is the ADSL, with $4 M B$ lines, but they tend to fall over, cables get stolen" (Participant D).

"They can't guarantee you no downtime, but I mean there are so many factors locally that they've got no control of. You know, you have a parastatal running the bulk of our bandwidth system" (E)

Systems performance and availability was associated with the risk of losing access to mission-critical systems and the resulting impact on business operations. Although bandwidth has become cheaper and more reliable in South Africa over the past decade, organizations and SaaS vendors are still faced with a number of challenges in addressing the risks associated with performance and availability of SaaS ERP software.

\subsection{Improved IT Reliability}

Most participants felt that SaaS ERP would be beneficial as a means of providing them with improved reliability of their core business software due to sophisticated platform technology, regular software updates, more effective backups and better systems redundancy. These sub-themes were considered major benefits of SaaS ERP software for SMEs interviewed. The perceived benefits of redundancy, backing up and received software updates were expressed as follows:

"I think it will be a safer option ...if they've got more expensive infrastructure with redundancy built in" $(\mathrm{Cl})$.

"...the other advantage is in terms of backing up and protecting of data...at least that becomes somebody else's responsibility” (E). “...it's probably more often updated...because it's been shared across a range of customers; it has to really be perfect all the time" (A1).

The benefit of improved IT reliability becomes more evident when one considers many SMEs often lack the required skills and resources to manage their on-premise enterprise systems effectively [35]; [36] thus making on-demand sourcing models such as SaaS more attractive:

"...having ERP software in-house that you maintain...does come with huge human resource constraint's." and "I'm not in the business of managing ERP systems, I'm in the business of book publishing and distribution...SaaS ERP makes all the sense in the world...you focus on just using it for your business rather than you run the product as well" (A1). 


\subsection{Data Security Risk}

Data security concerns were the fourth most dominant explanation and were related to concerns around the security and confidentiality of business information hosted on SaaS vendor infrastructure. Senior management provided the majority of responses. Data security concerns related to external hacking, risks from inside the SaaS vendor environment and from other clients sharing the infrastructure.

“...somebody somewhere at some level has got to have access to all of that information and it's a very off-putting factor for us" $(E)$.

"they've got a large number of other clients accessing the same servers" (D)

This confirms data security risk as one of the major inhibitors of SaaS ERP adoption [6], [12], [13]; [10]. Issues relating to vendor control over privileged access and segregation of data between SaaS tenants [29] appear to be strong concerns. Whilst SaaS vendors claim that their solutions are more secure, SaaS is generally considered suitable for applications with low data security and privacy concerns [34]. Ensuring that sufficient data security mechanisms are in place is also critical in terms of regulatory compliance when moving applications into the cloud [11]. South African organizations would also need to consider the new Protection of Personal Information Act.

\subsection{Loss of Control and Lack of Vendor Trust}

A number of participants associated SaaS ERP with a loss of control over their software and hardware components. They also raised concerns around trusting vendors with their mission-critical software solutions. This was the 3rd most dominant theme, with the majority of responses coming from senior management:

“...if they decide to do maintenance...there's nothing we can do about it...you don't have a choice" (C2).

"...they sort of cut corners and then you end up getting almost a specific-to-SLA type of service" (A2).

"Obviously the disadvantage is the fact that you are putting a lot of trust in another company and you've got to be sure that they are going to deliver because your entire business now is running on the quality of their staff, their turnaround times" (A1).

Participants felt that being reliant on vendors introduced risk that may affect the performance, availability and security of their mission critical applications. This is related to literature suggesting that organizations prefer in-house systems due to the risk of losing control over mission critical applications [34]. The linkage between lack of vendor trust and two other themes, systems performance and availability risk and data security risk, are consistent with Heart's [13] findings.

In this study, systems performance and availability risk was primarily related to bandwidth constraints (cost, internet latency and reliability). Thus, in the context of this study, the vendor trust aspect is very much related to SaaS vendors to ensure data security and ISPs to ensure internet connectivity uptime. 


\subsection{Functionality Fit and Customization Limitations}

Functionality fit refers to the degree to which ERP software matches the organizations functionality requirements. This was the least dominant concern with three participants raising concerns around lack of flexibility of SaaS ERP software due to concerns around the ability to customize the software.

“...it's got enhanced modules like book production....it gets quite complex, so that's for instance one of the modules that's quite niche that you don't get in typical ERP...I think if you were starting from scratch and you had nothing, the benefit would be that if we put (current ERP software) in, the product and the people who put it in for you understand the industry whereas...but would there be anyone within SAP or Oracle who really understands the book industry?" (A).

"I think the disadvantages are flexibility... most of them won't allow too much of customization" (B).

"They do have a certain amount of configurability in the program...but when it comes down to the actual software application, they (ERP vendor) say this is what you get...and if you want to change, that's fine but then we'll make the change available to everybody...so you lose your competitive advantage" $(D)$.

Functionality fit is considered an important factor which effects on-premise ERP software adoption [6] [37]. There are a limited number of vendors providing pure SaaS ERP software services [36] and SaaS ERP vendors are providing core ERP modules that cater for a wider market segment [18]. However, niche organizations that require highly specific functionality may find SaaS ERP software unsuitable, since the SaaS ERP business process logic may not fit their organization's functionality requirements.

Customization of ERP software is viewed as a means of accommodating the lack of functionality fit between the ERP software and the organization's functionality requirements, however, customization is limited within multi-tenancy SaaS ERP software [10]; [16].

Organizations could adopt SaaS ERP to fulfil standard functionality (accounting, warehousing, etc) whilst retaining in-house bespoke software to deliver specific functionality required but then integration complexity could become an issue. Various integration options are available for SaaS users. Platform as a service (PaaS) solutions provided by SalesForce.com (using Force.com and AppExchange) provide organizations with opportunities for purchasing 3rd party plugins that address integration needs [9]. However, changes to the SaaS software (e.g. software upgrades or customization) could break 3rd party interfaces [12]. Alternatively, organizations can make use of the standard web application programming interfaces (APIs) provided by the SaaS solution providers [16]; [12]. This enables SaaS vendors to continuously provide updates to functionality without breaking existing integrations [12]. However, these integration solutions have raised concerns around data security since multiple customers are transacting via the same web APIs [38]. 


\section{Conclusion}

The purpose of this research was to investigate reluctance by South African SMEs to consider the SaaS ERP business model. The following 7 themes emerged, in order from most significant to least, based on the participant perceptions, personal experience and organizational context (Figure 2).

1. Systems performance and availability risk (inhibitor)

2. Sunk cost and Satisfaction with existing system (inhibitor)

3. Loss of control and Vendor trust (inhibitor)

4. Data security risk (inhibitor)

5. Improved IT reliability (driver)

6. Perceived cost reduction (driver)

7. Functionality Fit and Customization Limitations (inhibitor)

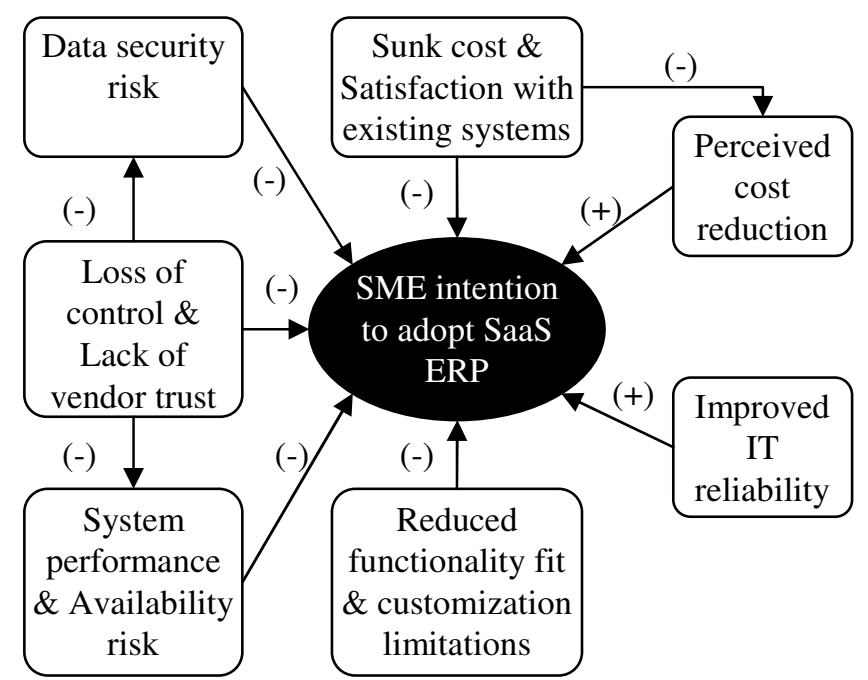

Fig. 2. An explanation of SME reluctance to adopt SaaS ERP. Negative effects are indicated by a negative sign (-) and positive effects by a positive sign (+).

Reluctance to adopt SaaS ERP was predominantly attributed to system performance and availability risk; data security risk; and loss of control and lack of vendor trust. Furthermore, loss of control and lack of vendor trust was found to increase the risks associated with systems performance and availability and the risks associated with data security. Thus organizations believed that in-house systems afforded them more control over their mission-critical software.

The presence of sunk costs appeared to negatively affect their perceptions towards the degree of cost reduction gains on offer with SaaS ERP software. Satisfaction with existing systems was associated with a lack of perceived benefits towards SaaS ERP software (why should we change when our current systems work?). 
There was an acknowledgement that the SaaS ERP model would provide improved IT reliability but it also would come with reduced functionality fit and customization limitations.

Lack of control and vendor trust concerns dominate in the South African environment and this is exacerbated by high risks of unavailability attributed to the poor network infrastructure of the country. Concerns regarding cable theft were even reported. The findings in this study are not necessarily representative of all organizations in South Africa and due to the lack of SaaS ERP vendor presence in South Africa, it is reasonable to assume that South African organizations lack sufficient awareness around SaaS ERP software capabilities and this may have introduced a significant degree of bias.

By providing empirically supported research into SaaS ERP adoption, this research has attempted to narrow the research gap and to provide a basis for the development of future knowledge and theory. SaaS vendors in particular may be able to benefit through comparing these findings with their own surveys and establishing new and innovative ways to address the inhibitors of SaaS ERP adoption intent.

These research findings suggest similarities between the satisfaction with existing systems factor and the diffusion of innovations (DOI) model construct "relative advantage". Other data segments (not included within this paper) also suggest a possible relationship with two other DOI constructs "observability" and "trialability". Therefore the use of DOI theory for future research into SaaS ERP adoption might improve understanding.

\section{References}

1. Seethamraju, R., Seethamraju, J.: Adoption of ERPs in a medium-sized enterprise-A case study. In: ACIS 2008 Proceedings, vol. 887 (2008)

2. Shehab, E., Sharp, M., Supramaniam, L., Spedding, T.: Enterprise resource planning: An integrative review. Business Process Management Journal 10(4), 359-386 (2004)

3. Berry, A., von Blottnitz, M., Cassim, R., Kesper, A., Rajaratnam, B., Van Seventer, D.E.: The Economics of Small, Medium and Micro Enterprises in South Africa, Trade and Industrial Policy Strategies, Johannesburg (2002)

4. Premkumar, G.: A meta-analysis of research on information technology implementation in small business. Journal of Organizational Computing and Electronic Commerce 13(2), 91-121 (2003)

5. Klaus, H., Rosemann, M., Gable, G.G.: What is ERP? Information Systems Frontiers 2(2), 141-162 (2000)

6. Buonanno, G., Faverio, P., Pigni, F., Ravarini, A., Sciuto, D., Tagliavini, M.: Factors affecting ERP system adoption: A comparative analysis between SMEs and large companies. Journal of Enterprise Information Management 18(4), 384-426 (2005)

7. Feuerlicht, G., Govardhan, S.: SOA: Trends and directions. Systems Integration, 149-155 (2009)

8. Benlian, A.: A transaction cost theoretical analysis of software-as-a-service (SAAS)-based sourcing in SMBs and enterprises. In: ECIS 2009 Proceedings, Paper 4 (2009)

9. Deyo, J.: Software as a service (SaaS): A look at the migration of applications to the web (2008), http://www.isy.vcu.edu/ jsutherl/Info658/SAAS-JER.pdf (retrieved May 7, 2011) 
10. Xin, M., Levina, N.: Software-as-a Service Model: Elaborating Client-Side Adoption Factors. In: ICIS 2008 Proceedings, vol. 86 (2008)

11. Armbrust, M., Fox, A., Griffith, R., Joseph, A.D., Katz, R., Konwinski, A., Lee, G., Patterson, D., Rabkin, A., Stoica, I., Zaharia, M.: A view of cloud computing. Communications of the ACM 53(4), 50-58 (2010)

12. Hai, H., Sakoda, S.: SaaS and integration best practices. Fujitsu Scientific and Technical Journal 45(3), 257-264 (2009)

13. Heart, T.: Who Is out there? Exploring Trust in the Remote-Hosting Vendor Community. In: ECIS Proceedings, Paper 2 (2007)

14. Kern, T., Willcocks, L.P., Lacity, M.C.: Application service provision: Risk assessment and mitigation. MIS Quarterly Executive 1(2), 113-126 (2002)

15. Hestermann, C., Anderson, R. P., Pang, C.: Magic quadrant for midmarket and tier 2oriented ERP for product-centric companies. Gartner, Inc. (2009),

http: / / www . wellpoint systems. com/pdf / GartnerMagicQuadrantforE RPMay2 009 .pdf (retrieved May 7, 2011)

16. Chong, F., Carraro, G.: Architecture strategies for catching the long tail. MSDN Library, Microsoft Corporation (2006)

17. Hestermann, C., Montgomery, N., Pang, C.: Magic quadrant for ERP for Product-Centric Midmarket Companies. Gartner, Inc. (2010), http: / / sme.news-sap.com/files / 2011/01/SAP-vol2art5.pdf (retrieved September 20, 2011)

18. Krigsman, M.: The 2011 focus experts' guide to enterprise resource planning. Focus Group, pp. 1-24 (2010), http://www. focus.com/research/erp/2011focus-experts-guide-enterprise-resource-planning-1/ (retrieved May 7, 2011)

19. Wailgum, T.: SaaS ERP Has Buzz, But Who Are the Real Players (2010), http: //www.cio.com/article/572463/(retrieved September 22, 2011)

20. Kisker, H.: ERP Grows Into The Cloud: Reflections From SuiteWorld 2011 (2011), http: //blogs.forrester.com/holger_kisker/11-05-16-

erp_grows_into_the_cloud_reflections_from_suiteworld_2011 (retrieved September 22, 2011)

21. Tornatzky, L.G., Fleischer, M.: The process of technological innovation. Lexington Books, Lexington (1990)

22. Walsham, G.: Interpretive case studies in IS research: Nature and method. European Journal of Information Systems 4(2), 74-81 (1995)

23. Saunders, M., Lewis, P., Thornhill, A.: Research methods of business students, 5th edn. Pearson Education/Prentice Hall, London (2009)

24. Small Business Act 102 (1996), http: / / www. info.gov.za/acts/1996/a102-96.pdf

25. Myers, M.D., Newman, M.: The qualitative interview in IS research: Examining the craft. Information and Organization 17(1), 2-26 (2007)

26. Thomas, D.R.: A general inductive approach for analyzing qualitative evaluation data. American Journal of Evaluation 27(2), 237 (2006)

27. Anfara, V.A., Brown, K.M., Mangione, T.L.: Qualitative analysis on stage: Making the research process more public. Educational Researcher 31(7), 28 (2002)

28. Aberdeen group: SaaS ERP: Trends and observations (2009), http://www.plex.com/download/AberdeenSaaSERPTrendsandObserva tions.pdf 
29. Brodkin, J.: Gartner: Seven cloud-computing security risks (2008), http: / / www. infoworld.com/d/security-central/gartner-sevencloud-computing-security-risks-853 ?page $=0,1$

30. Kaplan, J.: SaaS survey shows new model becoming mainstream. Cutter Consortium Executive Update 6(22) (2005)

31. Torbacki, W.: SaaS-direction of technology development in ERP/MRP systems. Archives of Materials Science 58, 58 (2008)

32. Premkumar, G., Roberts, M.: Adoption of new information technologies in rural small businesses. Omega: The International Journal of Management Science 27(4), 467-484 (1999)

33. Lee, H., Kim, J., Kim, J.: Determinants of success for application service provider: An empirical test in small businesses. International Journal of Human-Computer Studies 65(9), 796-815 (2007)

34. Benlian, A., Hess, T., Buxmann, P.: Drivers of SaaS-Adoption-An empirical study of different application types. Business \& Information Systems Engineering 1(5), 357-369 (2009)

35. Kamhawi, E.M.: Enterprise resource-planning systems adoption in Bahrain: Motives, benefits, and barriers. Journal of Enterprise Information Management 21(3), 310-334 (2008)

36. Ramdani, B., Kawalek, P.: SMEs \& IS innovations adoption: A review and assessment of previous research. Academia Revista Latinoamericana De Administración (39), 47-70 (2007)

37. Markus, M.L., Tanis, C.: The enterprise systems experience-from adoption to success. Framing the Domains of IT Research: Glimpsing the Future through the Past 173, 173-207 (2000)

38. Sun, W., Zhang, K., Chen, S.-K., Zhang, X., Liang, H.: Software as a Service: An Integration Perspective. In: Krämer, B.J., Lin, K.-J., Narasimhan, P. (eds.) ICSOC 2007. LNCS, vol. 4749, pp. 558-569. Springer, Heidelberg (2007) 